\title{
Wars are becoming less frequent: a response to Harrison and Wolf
}

Kristian Skrede Gleditsch and Steve Pickering

This is the final version submitted to EHR. The definitive version should be considered that published in Economic History Review, 67(1): 214-230, Feb. 2014.

Harrison and Wolf claim that interstate 'wars are becoming more frequent'. This is an alarming claim deserving serious attention. It is also a highly surprising claim, since recent conflict research tends to find the opposite: incidences of violent conflict are becoming less frequent. We argue that Harrison and Wolf's claim is incorrect. We show empirically that interstate wars are in fact becoming less frequent. Other data on tensions between states below war, such as the Interstate Crises Behavior data, also suggest a decline in conflict between states. We detail how Harrison and Wolf's analysis is misleading, highlighting how their findings primarily arise as a likely artefact of their uncritical use of the Militarized Interstate Disputes (MIDs) data, and explaining why MIDs cannot be interpreted as 'wars'. Given that Harrison and Wolf's basic premise is wrong, and wars are not becoming more frequent, we should be sceptical of their conclusions. We briefly revisit their suggested explanations for why wars may become more frequent in light of what we know about long-term trends in warfare and research on interstate war.

In their recent article, Harrison and Wolf claim that interstate '[w]ars are becoming more frequent'. ${ }^{2}$ This is an alarming claim deserving serious attention. It is also a highly surprising claim, since recent conflict research tends to find the opposite: the incidence of violent conflict is declining. ${ }^{3}$

We argue that Harrison and Wolf's claim is incorrect. We first show empirically that interstate wars are in fact becoming less frequent. Moreover, we show that other data on tensions between states below war, such as the Interstate Crises Behavior data, also suggest a decline in conflict between states. We then detail how Harrison and Wolf's analysis is misleading, highlighting how their findings primarily arise as a likely artefact of their uncritical use of the Militarized Interstate Disputes (MIDs) data, and explaining why MIDs cannot and should not be interpreted as 'wars'. Given that Harrison and Wolf's basic premise is wrong, and wars are not becoming more frequent, we should be sceptical of their conclusions. We revisit their suggested explanations for why wars may become more frequent in light of what we know about long-term trends in warfare and research on interstate war.

\section{I}

Trends in warfare and the frequency of war over time should in principle be relatively easy to assess empirically, given data and agreement on definitions and the underlying source material. There are a number of datasets in interstate wars, which differ in temporal coverage, underlying population of state actors that may be involved of conflict, and typologies of conflict. Prominent examples include the Correlates of War (COW) data on war, ${ }^{4}$ the Uppsala/PRIO Armed Conflict Dataset, ${ }^{5}$ and the Expanded War Data. ${ }^{6}$ Most of these datasets on war, however, share a common underlying definition of interstate war as armed conflict between two states involving at least 1,000 battle-deaths. By contrast, the Militarized Interstate Disputes dataset used by Harrison and Wolf does not have a minimum casualties threshold as a criterion for something to be considered a dispute. ${ }^{7}$ Hence, these data do not satisfy the conventional definition of what constitutes a 'war', unless one also would like to include common figurative uses of the term such as the 'war on drugs' or latent conflicts such as the Cold War. One may of course disagree with the conventional definition of war. However, Harrison and Wolf do not offer any discussion of why the standard definition of war is not appropriate or offer an alternative definition of war. Although we concur with Diehl et al. that the MID dataset can be helpful in addressing many central questions in the study of international conflict, it is a mistake to assume that MIDs are synonymous with wars. ${ }^{8}$ We will return to this issue later, but first review what conventional war data actually suggest about the frequency of interstate wars over time. 
We examine the recently updated interstate war data from the Expanded War Dataset. ${ }^{9}$ Much of the recent research on the decline in violent conflict also focuses on civil war, but we follow the example of Harrison and Wolf in restricting our analysis to interstate conflict. The Expanded War Dataset is based largely on the Correlates of War data, but uses a less Eurocentric definition of the population of independent states, especially for the nineteenth century. ${ }^{10}$ Many states, such as China and South American states, are not included as system members in the COW data for much of the nineteenth century, since they did not have diplomatic relations with the main European powers. As a result, all wars involving these states when they were not considered 'system members' are excluded from the COW interstate war data, leading to an undercount of interstate wars. By contrast, the Expanded War Dataset includes a number of conflicts between independent states that were not recognized as interstate wars in the COW data. We will revisit the implications of divergent definitions of the population of states in greater detail later. The Expanded War Dataset has been updated beyond 2007 (the end year for the V4.0 COW data) to 2010, based on the Uppsala/PRIO Armed Conflict Dataset. However, we note that there are no interstate events that claim more than 1,000 lives over this period, although civil wars do occur at this level of severity.

Figure 1 displays the total number of ongoing interstate wars by calendar year as a black bar for each annual count. Figure 1 shows that interstate wars are relatively infrequent events, and very rarely have more than three interstate wars been ongoing in any single year. Moreover, there are many years without any interstate wars. Remarkably, no interstate wars at all are recorded for the period 2004-10.

In our view, figure 1 suggests, if anything, a declining trend in interstate war. However, since humans are good at seeing patterns where none may exist, it is helpful to have a more formal criterion for what constitutes a trend and how to assess frequency over time. Harrison and Wolf use linear regression of time on the number of disputes, and we adopt the same approach here. ${ }^{11}$ Our aim is primarily to provide descriptive material about trends in wars over time rather than to decompose the time series into stochastic or systematic components that can possibly be attributed to specific covariates. ${ }^{12}$ However, like Harrison and Wolf, we also control for the number of states in the world, as the number of possible wars between states arguably could be a function of the interaction opportunities between states.

We first estimate a linear regression of time on the number of wars. This yields a negative but not statistically significant coefficient on year. ${ }^{13}$ The implied prediction from this model is shown as a thick dashed line in figure 1 . This suggests a declining rather than increasing linear trend over the entire period. However, the distribution of wars does not really suggest a uniform linear trend over the entire period. Linear regression by construction assumes a constant trend of time, which may not be appropriate here if there are structural shifts, or distinct trends in different phases over the time periods. We find that a simple non-linear specification based on time and time squared fits the data much better ( $R^{2}=0.145$ versus $R^{2}=0.02$ for the linear time trend). ${ }^{14}$ With a cubic time specification, all the coefficients for the time terms become statistically significant, and the coefficient for the number of states also becomes significant. The implied results from this model — shown by the dotted line in figure 1-suggest a curvilinear trend, where the number of wars increased up to the second half of the nineteenth century, then declined, again increasing with a new smaller peak around the period of decolonialization in the 1960s, and finally decreasing to an unprecedented low in the current period after the end of the Cold War.

Finally, since any parametric estimate of time will be sensitive to model specification, we present a non-parametric approach to assessing trends over time in the data, using a locally weighted regression estimate from the data on the numbers of wars over time. In figure 1 we display as a thin dashed line a LOWESS smoother, using a span of 0.2. ${ }^{15}$ This suggests a curvilinear trend similar to our cubed time specification, and the shape generally tracks our cubic regressionbased estimate closely, especially in the postwar decline in conflict and in the increase of wars up to German unification in the nineteenth century.

In our view, the trends displayed by the data in figure 1, as well as the various estimates discussed above, support the premise opposite to that of Harrison and Wolf, namely that there is a clear decline in the frequency of interstate wars. Some other data sources on interstate wars report slightly different absolute numbers of wars-for instance, the COW project has reclassified some interstate wars in the nineteenth century as 'extra-systemic', since one or more of the states were not recognized by the UK or France, and the Uppsala data are available only after 1945. However, these and other sources all suggest declining trends in the frequency of conflict over recent times similar to figure 1. As such, it is 
very difficult to see how the data on interstate war can be reconciled with Harrison and Wolf's claim of an increasing frequency of interstate war. The fact that other data sources on interstate war tend to give similar results, and in the opposite direction, should raise suspicion about the data examined by Harrison and Wolf and whether these can be considered evidence for an increasing frequency of interstate war.

\section{III}

In fairness, Harrison and Wolf do acknowledge that 'many indicators of interstate conflict have been flat or declining for decades or longer ... [including] the number of wars in each year since 1816, the number of military fatalities in each year since 1946, and the annual probability of bilateral interstate conflict since 1950'. However, the authors claim that the number of countries at war 'has moved persistently in the wrong direction'. ${ }^{16}$ They refer to findings presented by Hewitt as evidence for this claim. ${ }^{17}$ Hewitt's analysis is not limited to interstate wars and actually includes the civil wars in the UCDP data as well as conflicts below the 1,000 battle-deaths threshold. To examine empirically whether Harrison and Wolf's claim is consistent with conventional data on interstate war, we plot the number of participants in interstate wars in the Expanded War Dataset in figure 2. Although the absolute number of participants looks somewhat different from the count of interstate wars, we find a similar decline here over the twentieth century. Thus, contrary to Harrison and Wolf's claim, looking at participants in interstate war provides no evidence for an increasing frequency of interstate war. We conclude that the declining frequency in war in recent years holds irrespective of whether one looks at interstate wars or the number of participants in interstate wars.

\section{IV}

One might legitimately argue that the risk of war should be assessed not just in terms of the actual full-scale wars that we observe, but also in terms of the high-risk situations that plausibly could have escalated to become large wars, such as the Cuban Missile Crisis. Perhaps the dire warnings sounded by Harrison and Wolf reflect an increase in such crises with a high potential for war, even if they have tended not to escalate to war?

For reasons that we will detail later we believe that the MID data are inappropriate as a measure of the incidence of such close calls. However, the so-called Interstate Crisis Behavior (ICB) dataset provides one source that allows us to consider such situations empirically. According to Brecher and Wilkenfeld, interstate crises are defined by 'a change in type and/or an increase in intensity of disruptive ... interactions between two or more states, with a heightened probability of military hostilities', which is consistent with the notion of close calls that may not ultimately result in war. ${ }^{18}$ Figure 3 displays the number of ICBs for the period 1918-2007. These data again suggest a declining frequency of interstate crises, with the decline from the peak possibly even preceding the Cold War.

$\mathrm{V}$

The fact that common data sources on interstate war suggest a declining trend makes it puzzling that Harrison and Wolf can claim to find an increase in the frequency of interstate wars for 1870-2000. To understand this, it is instructive to examine in more detail the actual data that they use, namely the Correlates of War (COW) Militarized Interstate Dispute (MID) data.

\section{VI}

Jones, Bremer, and Singer define militarized interstate disputes as referring to 'united historical cases of conflict in which the threat, display or use of military force short of war by one member state is explicitly directed towards the government, official representatives, official forces, property, or territory of another state'. ${ }^{19}$ This definition highlights the fact that the MID dataset is primarily intended to supplement the COW project's existing data on wars through additional information on disputes short of war. Many researchers think of the disputes data as a superset of contentious interstate events that have some potential for escalation to war (although, as we will discuss in greater detail later, some researchers question whether this is appropriate). MIDs can have five levels of hostility: (1) no militarized action; (2) threat to use force; (3) display of force; (4) use of force; (5) war, that is, events with more than 1,000 deaths.

Harrison and Wolf suggest that it makes sense to analyse trends in conflictual interstate events with a less restrictive hostility level than the conventional threshold for war, since large-scale wars are so rare. ${ }^{20}$ However, we strongly believe that it is not warranted to consider disputes as 'wars', and it is highly problematic to assume that trends in MIDs provide 
a suitable basis for conclusion about trends in wars. In their analyses, Harrison and Wolf exclude MIDs with a hostility level below 3, but our argument also holds for disputes with a hostility level of 3 or 4 as neither of these can be considered to be as severe as war. In particular, we note that the 'use of force' category in the MID data (that is, level 4) includes events such as fishing disputes where one country's coastguard seizes a vessel from another state. Only 313 , or about 20 per cent, of the 1,553 MIDs that involved 'use of force' entail any recorded fatalities. Therefore, MIDs considered to include 'use of force' hardly correspond to what most people have in mind when they talk about interstate wars. Moreover, the 'use of force' category is actually the modal category in the MID data (constituting about twothirds of all MID events), and less than 5 per cent of the MIDs have hostility levels less than 3.

Since the entire basis for Harrison and Wolf's claim that '[w]ars are increasingly frequent, and the trend has been steadily upward since $1870^{21}$ rests on the inclusion of these events, it is essential to examine some of the MIDs with hostility levels of 3 and 4 to see whether these can plausibly be considered wars. For example, we have a level 4 event (that is, use of force) in 1997 between the US and Canada. It is worth quoting the COW description of this event in full:

\section{Between May 25, 1997 and May 27, 1997 Canada seized four American fishing boats in the Pacific Northwest after salmon quota negotiations between the two states broke down. Canada has repeatedly charged the United States with over-fishing in the area. All four boats were released after their Captains appeared in Canadian court and paid a fine. ${ }^{22}$}

In our view, a three-day dispute, ultimately resolved by fishermen paying fines, falls a long way short of war, and has little or no potential for escalation to interstate war. Indeed, there is no evidence here of any direct involvement by the US government, and we do not believe that any serious observer would consider a war between the US and Canada particularly likely in the wake of events of this type. More generally, all seizures of foreign vessels by a coastguard are considered 'use of force' in the MID data, although in practice it is rare for governments to be directly involved in such events. ${ }^{23}$ The management of international fisheries is an interesting issue in its own right, but not what most people have in mind when they think of war. Harrison and Wolf see the difference between MID categories as a difference in the degree of conflict; we see a clear difference in kind between wars and events short of war in the MID data.

One might argue that it is questionable whether such conflicts ought to be included in the MID data since they do not clearly involve states or agents sanctioned by states. ${ }^{24}$ However, it is incumbent on researchers to examine the data that form the basis for their claims and recognize that the MID data include many such events. Cohen and Weeks argue that approximately 7 per cent of all MIDs between 1945 and 2001 are interactions between coastguards and fishing vessels not linked to a demand by the home state, and Mitchell and Prins estimate that such fishing disputes constitute about 25 per cent of all the MIDs between democracies. ${ }^{25}$ By contrast, the ICB data include only two fishing disputes (ICB 254 and 263, the so-called 'cod wars' between Iceland and the UK), which unlike most fishing disputes did include explicit demands by state leaders.

Harrison and Wolf's analysis also included disputes with a hostility level of 3, involving 'display of force'. However, a perusal of the actual events included in these categories suggests that these do not seem to correspond with what Harrison and Wolf discuss as 'wars'. As a representative example, consider the narrative for dispute ID 4169: 'Mozambique condemns Swaziland for a border violation. Swaziland pledges to "better relations". No further details available'. In this case, the only evidence for the display of force appears to be the condemnation by Mozambique, and there does not seem to be any desire by Swaziland to escalate the issue. Such events may be interesting in their own right, but we do not think this can be considered a plausible 'war' in the conventional sense of the term.

\section{VII}

Aside from the issue of whether a militarized dispute should be considered a 'war' and whether all disputes ought to be given the same weight, the number of disputes counted in a given year obviously depends on whether specific incidents are considered as separate disputes or form part of an overall dispute, based on the underlying issue. To use a specific example, in the second so-called 'cod war', the Icelandic coastguard pursued 16 UK fishing vessels in January 1973. 
Should this be considered 16 distinct disputes, or part of the same dispute, as they all arise over a related controversy about the status of particular waters as domestic or international?

Harrison and Wolf count disputes in the MID data, but do not seem fully to have understood the criteria for distinguishing whether individual events count as a separate dispute or part of another dispute, and how these criteria are related to the severity of the dispute. The building block in the MID data is the concept of an incident or individual confrontation. The criteria for aggregating incidents into disputes, and for determining whether an incident is a new dispute or an incident in another dispute in the MID data, are complex. But they hinge on whether incidents are deemed to concern the same contentious issue, to occur in the same location, and to fall within six months of one another. ${ }^{26}$ However, the MID data explicitly stop counting new events once something is deemed a war, even if these involve

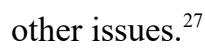

One implication of the MID coding rules is that more severe events are likely to give rise to fewer 'disputes'. Hence, they will be given systematically less weight in Harrison and Wolf's count of disputes. In particular, large-scale wars such as the First World War and Second World War constitute a single event in the COW MID dataset (IDs 257 and 258 respectively). By contrast, less serious militarized disputes such as those over the Spratly Islands, an archipelago in the South China Sea constituting approximately five square kilometres of land (presented in figure 4), are held to constitute 12 separate events. To give a sense of what is involved, we quote the narrative for MID 4329: 'Philippines increased patrols in the Spratlys as a result of the sighting of unspecified Chinese and Vietnamese vessels. Although some officials noted the sightings were part of "regular movement" in the disputed archipelago, the Philippine armed forces ordered increased patrols in the vicinity of Pagasa'.$^{28}$

Without belittling the importance of the Spratly Islands conflict, it seems questionable whether these events merit being counted as 12 wars or 6 times more important than two of the most bloody wars in human history, based on the absolute number of casualties. In our view, the inverse relationship between dispute numbers and severity makes the count of MIDs a questionable source for claims about global trends in conflict.

Our analyses so far have counted the number of wars or events. Harrison and Wolf break up events into bilateral disputes, where a given conflict could include one or more pairs of states confronting one another militarily. Although it may be useful to consider pairwise interactions within wars in dyadic analyses for many research questions, we believe that Harrison and Wolf's approach is problematic for assessing global trends and fails to recognize the structure of the MID data and its implications for dyadic analyses. It is highly unclear why the number of pairwise interactions should be preferred as a measure of the frequency of wars over the number of events, or other measures that also consider the magnitude of war such as the number of participants or the number of casualties in wars. ${ }^{29}$ If one insists on using dyadic data, then it must be recognized that the MID data simply list all participants on side A and B on a conflict, which does not necessarily mean that all states interacted or confronted each other militarily. For example, although Finland was on the opposite side of the UK and the US in the Second World War, neither of the states confronted each other militarily. The UK only declared war on Finland once the USSR joined the Allied side since Finland was already at war with the USSR, and the US never declared war on Finland. Neither the US nor the UK engaged in military action against Finnish armed forces. International conflict scholars are aware that simply creating dyads of all states listed as participants to disputes generates problems of 'false dispute dyads', inaccurate hostility levels, and incorrect starting dates. ${ }^{30}$ Researchers who wish to analyse the active dyadic participants normally use Maoz's dyadic version of the MID data to avoid such problems. ${ }^{31}$ Finally, if one wishes to aggregate dyadic data to assess global trends, then it would seem reasonable to consider the number of dyadic disputes relative to the number of dyads in the system. However, Harrison and Wolf acknowledge that the proportion of dyads in conflict has declined, even using the problematic dyadic data on all participants based on the standard MID data. ${ }^{32}$

\section{VIII}

The MID data may be plagued by a number of selection problems, and we will return to the issue of source availability biases later. However, one selection problem is built into the data by the construction. The MID data explicitly build on the COW project's delineation of states in the international system, documented most comprehensively by Singer and Small. ${ }^{33}$ This makes a comparison of counts of MIDs over time in the world at large highly problematic, in ways that do not seem to be appreciated by Harrison and Wolf.

The specific criteria for system membership in the COW project change over time. Prior to 1920, in general, members 
of the interstate system must, first, have a population above 500,000, and second, be 'sufficiently unencumbered by legal, military, economic, or political constraints to exercise a fair degree of sovereignty and independence', in practice assessed by whether states have formal diplomatic relations with Britain and France at or above the level of chargé d'affaires in the capital city. After 1920, Singer and Small classified 'a nation ... as a system member if it either: (a) was a member of the League of Nations or the United Nations at any time during its existence, or (b) met the half-million population minimum and received diplomatic missions from any two (rather than the specific two) major powers' ${ }^{34}$

As noted by Gleditsch and Ward, the COW criteria generate a list of system members at odds with common perceptions of independent states and difficulties for comparison over time. Many countries appear on the COW system membership list long after they were commonly regarded as independent states. Latin American states appear on the COW list many years after they achieved independence from Spain and long after they were active participants in international interactions. Many states that were never colonized (for example, China, Iran, and Japan) first appear on the list at seemingly arbitrary points, often just in time to be involved in a war with central European powers. Finally, after the Cold War we see a rush by many small microstates such as Palau (population barely 20,000) to join the UN, leading these to become included as system members in the COW list. Gleditsch and Ward propose an alternative list of independent states based on whether a unit, first, has a relatively autonomous administration over some territory; second, is considered a distinct entity by local actors or the state on which it is dependent on; and third, has a population greater than $250,000 .{ }^{35}$ As can be seen from figure 5, the COW list includes substantially fewer states than Gleditsch and Ward's list in the nineteenth century.

Do these differences in the definition of independent states make a difference for our conclusions about the frequency of war? For interstate wars the answer is clearly yes. Since the COW system list excludes many states without diplomatic relations with the European powers from the population of states up to 1920, it also excludes a number of states that actually engaged in interstate wars. As a result, the COW interstate war data exclude conflicts that normally would be considered conflicts between sovereign states and relegates these to another dataset on 'extrasystemic conflicts'. An example is the 1836-9 War of the Confederation, between the Peruvian-Bolivian Confederation on the one hand, and Chile on the other. Since the three states involved were not acknowledged by COW as existing until the end of the conflict (or in the case of Bolivia, not until nine years later), the conflict is not included in the COW interstate war data. Figure 6 shows the interstate war data in the Expanded War Data, based on the Gleditsch and Ward state list, and the number of these conflicts deemed extrasystemic in the COW war data. As can be seen, the share of excluded wars is substantial in the nineteenth century. An examination of the interstate war data from the COW project would suggest an increasing trend over the nineteenth century. However, this is to a large extent a function of the restrictive initial criteria for identifying states and changes over time, excluding many wars considered interstate by conventional criteria.

It is difficult to evaluate empirically the extent to which the restrictive and changing criteria for recognizing states as system members may affect trends in the MID data, since we do not have any comparable list of the disputes involving states not recognized in the COW list. However, based on what we know about interstate wars, the problem seems significant, and in our view makes these data unsuitable for comparisons over time.

\section{IX}

Many other researchers have shown that the MID dataset is one of the few sources that does not show a decline in conflict after the end of the Cold War. ${ }^{36}$ There is no universally accepted explanation for why this may be the case, but a number of different suggestions have been proposed. It is of course possible that there is a decline in violent conflict in general, and at the same time we see a dramatic increase in minor disputes or contentious issues that do not escalate to significant violence. In our view, this is unlikely, and we believe a more plausible explanation is that the lower-level militarized disputes tend to be severely undercounted the further back we go in time, due to systematic differences in the availability of sources. A perusal of the narratives of the MID data suggests that many of the recent recorded MIDs are relatively obscure. It is very difficult to find any information on many events in the most recent update of the MID data. Given the explosion of available information sources over the last decade, it seems less likely that one would be able to find consistent documentation for minor militarized events such as fishing disputes for earlier periods of time. This is likely to give rise to a systematic downward bias the further back one goes in time. We surmise that much of the apparent increase in MIDs is likely to be a result of greater media coverage over time. Although it is difficult to evaluate such selection problems empirically, we submit that such selection problems are highly probable and likely to make the MID data very problematic for claims about global trends over time. Finally, even if we disregard the likely selection 
biases leading to a large number of lower-level MIDs in more recent years and if it actually is correct that we see an increasing frequency of contentious issues and disputes, the MID data still indicate that few of these escalate to lethal violence. Hence, the data hardly suggest an 'increasing frequency of war'. Above all, they suggest a marked tendency for disputes to be less likely to escalate to war over time. This does not seem consistent with Harrison and Wolf's claim about an increasing frequency of war. Indeed, the observed decline in war is even more remarkable if there actually is an increase in lower-level disputes and a lower rate of escalation to war.

\section{$\mathrm{X}$}

In fairness to Harrison and Wolf, many of the issues and problems in the MID data discussed above remain unappreciated by conflict researchers, who often use information on disputes to make inferences about wars, assuming that the causes of war mirror the predictors of disputes. However, research seeking to account for MIDs and escalation to war tends to have a very different focus than Harrison and Wolf, and in our view the problems identified here may not apply to the same extent in these studies.

Existing studies rarely use these data for assessing global trends in conflict between states over time, but typically examine outbreaks of disputes at the level of individual dyads or pairs of states, and how the risk of a dispute may be accounted for by differences in various characteristics of the states in a dyad (for example, level of development, contentious claims, or political institutions) as well as possible changing characteristics of the international system (such as the distribution of power or the presence/absence of international institutions). Controlling for dyadic characteristics and comparing disputes for the same dyad profile can in part address some of the problems arising from systematic biases in aggregate analysis over time. Harrison and Wolf review some of the suggested explanations of factors influencing the risk of war. However, they examine only the aggregate distributions of these features at the global level, rather than how the characteristics of individual dyads influence differences in the risk of disputes. This disregards completely how inferences focusing on aggregate characteristics summed over individual units are susceptible to a host of ecological fallacy problems, outlined by Robinson and later popularized by Singer in the study of international war. ${ }^{37}$ Furthermore, most analyses of the MID data examine only the post- 1945 period, hence avoiding the problems of the changes in membership criteria of the COW system after 1945.

\section{XI}

On the basis of our analysis, we take issue with Harrison and Wolf's claim to find an increasing trend in interstate wars. Indeed, we believe that a more reasonable review of the data suggests the opposite, and that wars are becoming less frequent. We have detailed why we do not find the empirical material presented by Harrison and Wolf to be compelling.

Harrison and Wolf proceed from their assertion that war is increasing to speculate on the possible causes in the latter part of their article. We believe that their initial premise that such an increasing trend exists is misguided, and Harrison and Wolf's arguments strike us as post hoc speculation to account for the alleged trend, rather than being derived from any explicit theoretical justification. We also believe that many of their claims ignore the potential ecological fallacies in assessing the generally dyadic arguments in existing research on interstate conflict with aggregate global data. ${ }^{38}$

More generally, however, any effort to assess and account for global trends in warfare must first start by recognizing what is encompassed by the available data, what sort of inferences they can and cannot support, and their possible limitations. In our view, the most plausible interpretation of the available evidence suggests that wars are declining, and that the possible increase in lower-level disputes (which may be an artefact of selection biases) if anything goes together with a tendency for these to escalate to war less often. A more productive avenue for research on trends in conflict would be to consider what factors may explain why we observe these trends. There is a large literature on the thesis of the decline in violent conflict. ${ }^{39}$ We cannot aspire to provide new contributions within the scope of this article or even to do full justice to the existing literature. However, we would like to offer some brief comments on why some of the key features highlighted by Harrison and Wolf may actually contribute to the decline in conflict and its severity.

Harrison and Wolf highlight the declining costs of destructive capacity and technologies as a permissive condition for conflict. In our view, although military technology probably has become relatively cheaper, the risk of war will depend on relative capabilities rather than the absolute costs of arms, and many of these decreases in costs apply to all countries 
alike. The willingness to resort to war should depend on a country's prospects of winning in a contest rather than just the costs of armaments per se. The likelihood of one country, A, prevailing in a dyadic contest with another country, B, can be thought of as a function of the ratio of their military capabilities. Hence, the fact that military capabilities become cheaper for A may not change the relative balance if they also become cheaper for B, and most researchers dispute that there is any simple direct relationship between the costs of armaments and the risk of conflict. ${ }^{40}$

Furthermore, Harrison and Wolf's discussion of the costs of war focuses solely on expenditure on destructive capacity and completely neglects the costs of war in terms of the destruction caused by war and the opportunity costs of violent conflict. Any serious analysis of conflict must consider how the full costs of war shape the incentives of actors, and their incentives to reach alternative solutions to contentious issues without the use of violence. ${ }^{41}$ From a bargaining perspective, all wars must eventually come to an end, and if war is costly then the parties should have an incentive to reach an agreement reflecting the likely settlement after a war, without paying the costs of fighting the war. There is no reason to suspect that states no longer have contentious issues - indeed, one might expect that these have increased with greater interaction and globalization. However, development, democratization, and capitalism may have made it easier for states to reach agreement, and avoid escalation to war, and more costly to fail to reach agreement. For example, existing research at the dyadic level suggests that democratic states are more likely to settle their disputes peacefully, possibly since they can externalize their internal dispute resolution mechanisms or delegate dispute arbitration to international institutions. ${ }^{42}$ Moreover, states with more trade and more extensive economic relations are likely to have higher opportunity costs from escalation to war and may have more opportunities to signal intent and reach resolution by means other than military force. ${ }^{43}$ The trend towards a decline in war may also be facilitated by important global macro-trends such as increases in education and urbanization, which have been shown to foster attitudes that make people less likely to glorify violence and more likely to seek rational compromise. ${ }^{44}$

We agree with Harrison and Wolf that much remains to be discovered about war and why it has changed over time, and that much additional research is needed. However, it would be a mistake to start this line of research with a false premise, misleadingly presented as an empirical fact.

\section{Footnote references}

Bennett, D. S. and Stam, A. C., 'Research design and estimator choices in the analysis of interstate dyads: when decisions matter', Journal of Conflict Resolution, 44 (2000), pp. 653-85.

Brecher, M. and Wilkenfeld, J. F., A study of crisis (Ann Arbor, Mich., 1997).

Cleveland, W. S., 'Robust locally weighted regression and smoothing scatterplots', Journal of the American Statistical Association, 74 (1979), pp. 829-36.

Diehl, P. F., Pollins, B., Palmer, G., Hensel, P., Gibler, D., Regan, P., Stoll, R., Ray, J. L., Geller, D., Gochman, C., and Bremer, S., 'Collaborative research on updating the Militarized Dispute Dataset', proposal submitted to the National Science Foundation (1999).

Dixon, W. J., 'Democracy and the peaceful settlement of international conflict', American Political Science Review, 88 (1994), pp. 14-32.

Elias, N., The civilizing process: sociogenetic and psychogenetic investigations (Oxford, 2000).

Fearon, J. D., 'Rationalist explanations for war', International Organization, 49 (1995), pp. 379414.

Ferguson, N., The cash nexus: money and power in the modern world, 1700-2000 (2001).

Gartzke, E. A., 'The capitalist peace', American Journal of Political Science, 51 (2007), pp. 16691. 
Gleditsch, K. S., 'A revised list of wars between and within independent states, 1816-2002', International Interactions, 30 (2004), pp. 231-62.

Gleditsch, K. S. and Beardsley, K. C., 'Issues in international data collection', in R. A. Denemark, ed., The international studies encyclopedia (New York, 2010), pp. 4705-25.

Gleditsch, K. S., Salehyan, I., and Schultz, K., 'Fighting at home, fighting abroad: how civil wars lead to interstate disputes', Journal of Conflict Resolution, 52 (2008), pp. 479-506.

Gleditsch, N. P. and Hegre, H., 'Peace and democracy: three levels of analysis', Journal of Conflict Resolution, 41 (1997), pp. 283-310.

Gleditsch, N. P., Wallensteen, P., Erikson, M., Sollenberg, M., and Strand, H., 'Armed conflict, 1945-99: a new dataset', Journal of Peace Research, 39 (2002), pp. 615-37.

Gleditsch, K. S. and Ward, M. D., 'A revised list of independent states since the Congress of Vienna', International Interactions, 25 (1999), pp. 393-413.

Goldstein, J. S., Winning the war on war: the decline of armed conflict worldwide (New York, 2011).

Hamilton, J. D., Time series analysis (Princeton, N.J., 1994).

Harrison, M. and Wolf, N., 'The frequency of wars', Economic History Review, 65 (2012), pp. $1055-76$.

Hewitt, J. J., 'Unpacking global trends in violent conflict, 1946-2005', in J. J. Hewitt, J.

Wilkenfeld, and T. R. Gurr, eds., Peace and conflict 2008 (Boulder, Co., 2008), pp. 107-18.

Human Security Centre, Human security report 2005: war and peace in the 21st century (Oxford, 2005).

Jones, D. M., Bremer, S. A., and Singer, J. D., 'Militarized interstate disputes, 1816-1992: rationale, coding rules, and empirical applications', Conflict Management and Peace Science, 15 (1996), pp. $163-213$.

Lacina, B. A., Gleditsch, N. P., and Russett, B. M., 'The declining risk of death in battle', International Studies Quarterly, 50 (2006), pp. 673-80.

Maoz, Z., 'Dyadic Militarized Interstate Disputes dataset (version 2.0)' (2005)

http://psfaculty.ucdavis.edu/zmaoz/dyadmid.html (accessed 3 Dec. 2012).

Mitchell, S. M. and Prins, B. C., 'Beyond territorial contiguity: issues at stake in democratic militarized interstate disputes', International Studies Quarterly, 43 (1999), pp. 169-83.

Mueller, J., Retreat from doomsday: the obsolescence of major war (New York, 1989).

Payne, J. L., A history of force: exploring the worldwide movement against habits of coercion, bloodshed, and mayhem (Sandpoint, Ida., 2004).

Pinker, S., The better angels of our nature: why violence has declined (New York, 2011).

Polachek, S. and Xiang, J., 'How opportunity costs decrease the probability of war in an incomplete information game', International Organization, 64 (2010), pp. 133-44. 
Reed, W. L., 'Information, power, and war', American Political Science Review, 97 (2003), pp. 633-41.

Robinson, W. S., 'Ecological correlations and the behavior of individuals', American Sociological Review, 15 (1950), pp. 351-7.

Russett, B. M. and Oneal, J. R., Triangulating peace: democracy, interdependence, and international organizations (New York, 2001).

Sarkees, M. R., and Wayman, F., Resort to war: a data guide to inter-state, extra-state, intra-state, and non-state wars, 1816-2007 (Washington, DC, 2010).

Singer, J. D., 'The level-of-analysis problem in international relations', World Politics, 14 (1961), pp. 77-92.

Singer, J. D. and Small, M., The wages of war, 1816-1965: a statistical handbook (New York, 1972).

Small, M. and Singer, J. D., Resort to arms: international and civil wars, 1816-1980 (Beverly Hills, Calif., 1982).

Smith, R. P., 'Models of military expenditure', Journal of Applied Econometrics, 4 (1989), pp. 34559.

Thyne, C. L., 'ABCs, 123's, and the golden rule: the pacifying effect of education on civil war, 1980-1999', International Studies Quarterly, 50 (2006), pp. 733-54.

Weeks, J. and Cohen, D. K., 'Red herrings? Fishing disputes and interstate conflict', paper presented at the 50th Annual Convention of the International Studies Association, New York (15-18 Feb. 2009).

$<$ /bibliography $>$

Figure 1. Number of interstate wars

Notes: Grey bars: no. of interstate wars. The superimposed thick dashed line indicates the fitted values of a linear regression on time and the no. of states; the dotted line displays the fitted values from a regression with time, time squared, and the no. of states; and the thin dashed line indicates a non-parametric trend estimate for the no. of wars over time.

Figure 2. Number of interstate war participants

Notes: Grey bars: no. of interstate war participants. The superimposed thick dashed line indicates the fitted values of a linear regression on time and the no. of states; the dotted line displays the fitted values from a regression with time, time squared, and the no. of states; and the thin dashed line indicates a non-parametric trend estimate for the no. of interstate war participants over time.

Figure 3. Number of interstate crises

Notes: Grey bars: no. of interstate crises. The superimposed thick dashed line indicates the fitted values of a linear regression on time and the no. of states; the dotted line displays the fitted values from a regression with time, time squared, and the no. of states; and the thin dashed line indicates a non-parametric trend estimate for the no. of interstate crises over time. 
Figure 4. The Spratly Islands

Note: This is an archipelago composed of less than five square kilometres of land, but representing six times more MIDs than the First and Second World Wars combined.

Figure 5. Number of independent states

Notes: Dotted line: according to the COW system membership list; solid line: Gleditsch and Ward's list of independent states (Gleditsch and Ward, 'Revised list').

Figure 6. Number of interstate wars

Notes: Black area: no. of interstate wars in the Expanded War Data (black area); grey area: shares of these wars considered extrasystemic by the COW system.

*Author Affiliation: University of Essex.

${ }^{1}$ We thank Erik Gartzke, Ismene Gizelis, Nils Petter Gleditsch, Tim Hatton, Andrew Mack, Steven Pinker, and workshop participants at Essex for helpful discussions and comments. The authors are listed in alphabetical order; equal authorship is implied. Gleditsch would like to acknowledge the support of the Research Council of Norway (180441/V10).

${ }^{2}$ Harrison and Wolf, 'Frequency of wars', p. 1055.

${ }^{3}$ See, for example, Human Security Centre, Human Security Report 2005; Gleditsch and Beardsley, 'Issues'; Goldstein, Winning the war; Mueller, Retreat from doomsday; Pinker, Better angels.

${ }^{4}$ Sarkees and Wayman, Resort to war; Small and Singer, Resort to arms.

${ }^{5}$ Gleditsch, Wallensteen, Erikson, Sollenberg, and Strand, 'Armed conflict'.

${ }^{6}$ Gleditsch, 'Revised list'.

${ }^{7}$ Jones, Bremer, and Singer, 'Militarized interstate disputes'.

${ }^{8}$ Diehl, Pollins, Palmer, Hensel, Gibler, Regan, Stoll, Ray, Geller, Gochman, and Bremer, 'Collaborative research'.

${ }^{9}$ Version 2.0, released 28 Dec. 2011.

${ }^{1 \circ}$ For a discussion of an earlier release, see Gleditsch, 'Revised list'.

${ }^{11}$ Harrison and Wolf actually use the log of the number of disputes. We use the actual number of wars since many years have 0 wars (for which the logarithm is not defined) and since the distribution of the number of wars is not particularly skewed.

${ }^{12}$ Hamilton, Time series analysis.

${ }^{13}$ More specifically, we find the following coefficient estimates: no. of interstate wars $=7.195-0.003 \square$ year $-0.001 \square$ no. of states, $R^{2}=0.02$, with neither states nor year significant.

${ }^{14}$ No. of interstate wars $=-1157.22+1.235 \square$ year $-0.00033 \square$ year $^{2}+0.038 \square$ no. of states, $R^{2}=0.145$. 
${ }^{15}$ See Cleveland, 'Robust locally weighted regression'.

${ }^{16}$ Harrison and Wolf, 'Frequency of wars', p. 1056.

${ }^{17}$ Hewitt, 'Unpacking global trends'.

${ }^{18}$ Brecher and Wilkenfeld, Study of crisis, pp. 4-5.

${ }^{19}$ Jones et al., 'Militarized interstate disputes', p. 163.

${ }^{20}$ Harrison and Wolf, personal communication.

${ }^{21}$ Harrison and Wolf, 'Frequency of wars', p. 1055.

${ }^{22} \mathrm{COW}$ event ID 4183.

${ }^{23}$ See Weeks and Cohen, 'Red herrings?'.

${ }^{24}$ For example, ibid.; Gleditsch, Salehyan, and Schultz, 'Fighting at home'.

${ }^{25}$ Weeks and Cohen, 'Red herrings?'; Mitchell and Prins, 'Beyond territorial contiguity'.

${ }^{26}$ Jones et al., 'Militarized interstate disputes', pp. 174-7.

${ }^{27}$ Ibid., p. 170.

${ }^{28}$ Narrative for MID 4329.

${ }^{29}$ Both of these suggest decreasing rather than increasing trends: see our previous discussion above on the former; and Lacina, Gleditsch, and Russett, 'Declining risk of death', on the latter.

${ }^{30}$ See Bennett and Stam, 'Research design'; Maoz, 'Dyadic Militarized Interstate Disputes '. Many dyadic analyses of conflict only consider the originators of a conflict, or the participants active at the outset, as the factors influencing the outbreak of a dispute may differ from the factors leading subsequent states to join ongoing disputes.

${ }^{31}$ Maoz, 'Dyadic Militarized Interstate Disputes'.

${ }^{32}$ Harrison and Wolf, 'Frequency of wars', p. 1055. See also Gleditsch and Beardsley, 'Issues'.

${ }^{33}$ Singer and Small, Wages of war.

${ }^{34}$ Ibid., p. 20. In practice, the explicit criteria are neither sufficient nor strictly necessary to replicate the COW list, as many countries have been included or excluded from the COW system membership list based upon qualitative judgements. For example, Singer and Small (ibid., p. 21) excluded India, Slovakia, and Manchukuo, although they met the criteria, and included China, Mongolia, Nepal, Saudi Arabia, and Yemen, despite their failure to meet either of the post-1920 criteria.

${ }^{35}$ Gleditsch and Ward, 'Revised list'. Gleditsch and Ward suggest an alternative list of microstates, based on their conventional dates of independence, for researchers that wish to include these. For example, since San Marino is often considered the world's oldest republic, it seems odd to consider this microstate 'relevant' after it joins the UN in 1992 and completely irrelevant before this.

${ }^{36}$ See, for example, Gleditsch and Beardsley, 'Issues'. 
${ }^{37}$ Robinson, 'Ecological correlations'; Singer, 'Level-of-analysis problem'.

${ }^{38}$ See also Gleditsch and Hegre, 'Peace and democracy'.

${ }^{39}$ For example, Goldstein, Winning the war; Payne, History of force; Pinker, Better angels.

${ }^{40}$ See, for example, Smith, 'Models of military expenditure'.

${ }^{41}$ See, for example, Fearon, 'Rationalist explanations'; Reed, 'Information, power, and war'.

${ }^{42}$ See, for example, Dixon, 'Democracy'; Russett and Oneal, Triangulating peace.

${ }^{43}$ See, for example, Ferguson, Cash nexus; Gartzke, 'Capitalist peace'; Polachek and Xiang, 'Opportunity costs'.

${ }^{44}$ See, for example, Elias, Civilizing process; Pinker, Better angels; Thyne, 'ABC's'. 